\title{
What models of change can be used to implement change in postgraduate medical education?
}

This article was published in the following Dove Press journal:

Advances in Medical Education and Practice

\author{
Taha Mahmood \\ Barts and The London School of \\ Medicine and Dentistry, London, UK
}

\section{Dear Editor}

I greatly enjoyed reading the article "Are they ready? Organizational readiness for change among clinical teaching teams" by Bank et al. ${ }^{1}$ This explored whether organizational readiness for change (ORC) could facilitate curriculum change in postgraduate medical education (PGME). The study reported that clinical staff felt responsible for change, viewing "program directors" as their leaders, and as being part of a learning culture. However, the study reported difficulties in implementation due to insufficient managerial support and the absence of an implementation plan. This included the "absence of timelines", as well as "insufficient re-evaluation cycles, training facilities and financial resources". 1

As a keen observer, I would like to bring to the attention of the readers the opportunity to use previously described models of change in healthcare settings. If these models were applied, they could enhance and guide the implementation process in PGME. The models of change that have been used in healthcare settings include Kotter's Model, ${ }^{2}$ Lewin's Model, ${ }^{3}$ balanced scorecard, ${ }^{4}$ and Gantt Charts. ${ }^{5}$

Kotter emphasizes the importance of a conducive environment for change which he calls the "climate for change". He focuses on the need to engage and enable those around you. ${ }^{2}$ This seems to have occurred in Bank et al's study as they report that clinical staff are "committed to change" and "working together as a team". ${ }^{1}$ However, Kotter insists on achieving short-term wins for successful implementation. Therefore, I feel the addition of some key performance indicators or metrics in the implementation plan may help to demonstrate the benefits of change and be parameters of success. ${ }^{2}$

Lewin on the other hand is more concerned with readiness for change as a precursor to its implementation and change becoming permanent. ${ }^{3}$ In Bank's study, despite clinical staff not showing any resistance, their readiness for change is questionable as staff need to be trained to deliver the new curriculum. When confident, staff are more likely to participate and take ownership of the change. Therefore, I suggest that the implementation plan should consider how staff can be facilitated and supported to develop new skills.

The "absence of tasks and timelines" can be overcome by using a balanced scorecard. ${ }^{1}$ This provides a framework for implementation as for each objective there are measures, targets, and initiatives. A balanced scorecard builds consensus providing visual representation and allows for the early detection of negative outcomes. I
Correspondence: Taha Mahmood Barts and The London School of Medicine and Dentistry, Garrod Building, Turner Street, Whitechapel, London, EI 2AD, UK

Email t.mahmood@smdı3.qmul.ac.uk 
believe that the lack of an implementation plan described by Bank et al could be helped by using a balanced scorecard as it allows for a culture of measurement, greater dialogue between program directors and clinical staff, as well as an improved understanding of why competency-based medical education is superior. ${ }^{4}$

Furthermore, a visual aid such as a Gantt Chart can be used for helping implementation of change. This timetables the expected time to complete certain tasks and allocation of resources. ${ }^{5}$ I feel that given the shortcomings in "tasks and timelines, evaluation cycles, and financial resources," this may be effective in monitoring implementation. ${ }^{1}$

To conclude, the above-listed formal planning tools could help to implement change in PGME. Underpinning these tools are principles that assess the impact on the organization, the management of uncertainty and resistance, as well as the sources of responsibility. I suggest that Bank et al may consider this approach and hope that this letter reaches them and other readers who might be looking for a successful implementation of change in PGME.

\section{Disclosure}

The author reports no conflicts of interest in this communication.

\section{References}

1. Bank L, Jippes M, Leppink J, et al. Are they ready? Organizational readiness for change among clinical teaching teams. Adv Med Educ Pract. 2017;8:807-815.

2. Baloh J, Zhu X, Ward M. Implementing team huddles in small rural hospitals: how does the Kotter model of change apply? J Nurs Manag. 2017;8:148-153.

3. Batras D, Duff C, Smith B. Organizational change theory: implications for health promotion practice. Health Promot Int. 2014;31(1):231-241.

4. Hwa M, Sharpe B, Wachter R. Development and implementation of a balanced scorecard in an academic hospitalist group. J Hosp Med. 2013;8(3):148-153.

5. Langabeer II JR, Helton J. Health Care Operations Management. Sudbury, MA: Jones and Bartlett Publishers; 2008:155-157. 


\section{Authors' reply \\ Lindsay Bank ${ }^{1,2}$ \\ Mariëlle Jippes ${ }^{3}$ \\ Jimmie Leppink ${ }^{4}$ \\ Albert JJA Scherpbier ${ }^{4}$ \\ Corry den Rooyen ${ }^{5}$ \\ Scheltus J van Luijk ${ }^{6}$ \\ Fedde Scheele ${ }^{1,2,7}$}

'Department of Healthcare Education, OLVG Hospital, Amsterdam, the Netherlands; ${ }^{2}$ Faculty of Earth and Life Sciences, Athena Institute for Transdisciplinary Research, VU University, Amsterdam, the Netherlands; ${ }^{3}$ Department of Plastic Surgery, Erasmus Medical Centre, Rotterdam, the Netherlands; ${ }^{4}$ Faculty of Health, Medicine and Life Sciences, School of Health Professions Education, Maastricht University, Maastricht, the Netherlands; ${ }^{5}$ Movation BV, Maarssen, the Netherlands; ${ }^{6}$ Department of Healthcare Education, Maastricht University Medical Center, Maastricht, the Netherlands; ${ }^{7}$ School of Medical Sciences, Institute for Education and Training, VU University Medical Center, Amsterdam, the Netherlands

Correspondence: Lindsay Bank

Department of Healthcare Education, OLVG Hospital, Jan Tooropstraat 164, I06I AE Amsterdam, the Netherlands

Tel +3l 205108292

Email bank.lindsay@gmail.com

\section{Dear Editor}

Thank you for the opportunity to respond to Mr Mahmood's letter. We appreciate the insightful comments made by $\mathrm{Mr}$ Mahmood in regard to our article "Are they ready? Organizational readiness for change among clinical teaching teams." He describes several change models that can be used to implement change in postgraduate medical education (PGME) based on strategies previously used in healthcare settings. Additionally, he suggests the combined use of parts of these models for change in PGME.

As noted in our manuscript, change is known to be challenging and requires a proper change management strategy to improve the chances for success. ${ }^{1}$ Indeed, on a limited scale, change management strategies are used in healthcare settings. Unfortunately, these strategies rarely make a transfer into change processes in PGME. Therefore, for this study, we chose organizational readiness for change (ORC) as our change model, or "lens," to improve the chances for successful change in PGME. The rationale for choosing this model is that it was previously, and successfully, used in undergraduate medical education ${ }^{2}$ which made us believe it could be of value in PGME as well.

That said, we completely agree with Mr Mahmood that there is more than one way to skin a cat and that readiness for change is just one of many possible lenses to approach change processes. Undeniably, other change management strategies can bring valuable assets to the table as well. In our view, the use of ORC as a lens to look at a change process does not exclude the use of any other strategies or lenses. The assessment of ORC, in this case with using the questionnaire "Specialty Trainings Organizational Readiness for Change" (STORC), ${ }^{3}$ mainly serves as a diagnostic tool prior or during a change process. It leaves freedom for change leaders to use other change models as well. For instance, the assessment of ORC could help to determine in which of the eight stages of Kotter's change model problems may be expected. ${ }^{4,5}$

To conclude, we can only agree that other change models besides or combined with the assessment of ORC could be useful in PGME. Therefore, we strongly encourage change leaders to demonstrate which change models are used in their educational settings and share their best practices in order for others to learn from.

\section{Disclosure}

The authors report no conflicts of interest in this communication.

\section{References}

1. Bank L, Jippes M, Leppink J, et al. Are they ready? Organizational readiness for change among clinical teaching teams. Adv Med Educ Pract. 2017;8:807-815.

2. Jippes M, Driessen EW, Broers NJ, Majoor GD, Gijselaers WH, van der Vleuten CP. A medical school's organizational readiness for curriculum change (MORC): development and validation of a questionnaire. Acad Med. 2013;88(9):1346-1356.

3. Bank L, Jippes M, Leppink J, et al. Specialty Training's Organizational Readiness for curriculum Change (STORC): validation of a questionnaire. Adv Med Educ Pract. 2018;9:75-83.

4. Kotter JP. Leading Change. Boston, MA: Harvard Business School Press; 1996.

5. Cohen DS. The Heart of Change Field Guide: Tools and Tactics for Leading Change in your Organization. Boston, MA: Harvard Business School Press; 2009. 
Dove Medical Press encourages responsible, free and frank academic debate. The content of the Advances in Medical Education and Practice 'letters to the editor' section does not necessarily represent the views of Dove Medical Press, its officers, agents, employees, related entities or the Advances in Medical Education and Practice editors. While all reasonable steps have been taken to confirm the content of each letter, Dove Medical Press accepts no liability in respect of the content of any letter, nor is it responsible for the content and accuracy of any letter to the editor.

Advances in Medical Education and Practice

Dovepress

\section{Publish your work in this journal}

Advances in Medical Education and Practice is an international, peerreviewed, open access journal that aims to present and publish research on Medical Education covering medical, dental, nursing and allied health care professional education. The journal covers undergraduate education, postgraduate training and continuing medical education including emerging trends and innovative models linking education, research, and health care services. The manuscript management system is completely online and includes a very quick and fair peer-review system. Visit http://www.dovepress.com/testimonials.php to read real quotes from published authors.

Submit your manuscript here: http://www.dovepress.com/advances-in-medical-education-and-practice-journal 